\title{
Gender differences in thyroid function and obesity among finnish women and men. The FIN-D2D-study
}

\author{
Juha Saltevo', Hannu Kautiainen ${ }^{2,3,4}$, Pekka Mäntyselkä4,5, Antti Jula ${ }^{6}$, Sirkka Keinänen-Kiukaanniemi ${ }^{7,8}$, Eeva Korpi-Hyövälti ${ }^{9}$, Leo \\ Niskanen $^{10}$, Heikki Oksa ${ }^{11,12}$, Timo Saaristo ${ }^{11}$, and Mauno Vanhala ${ }^{13,4}$ \\ ${ }^{1}$ Department of Medicine, Central Finland Central Hospital, 40620 Jyväskylä, Finland \\ ${ }^{2}$ Unit of Primary Health Care, Helsinki University Central Hospital, Finland \\ ${ }^{3}$ Department of General Practice, University of Helsinki, Helsinki, Finland \\ ${ }^{4}$ Primary Health Care Unit, Kuopio University Hospital, Kuopio, Finland \\ ${ }^{5}$ Institute of Public Health and Clinical Nutrition, Primary Health Care, School of Medicine, University of Eastern Finland, Kuopio, Finland \\ ${ }^{6}$ National Institute for Health and Welfare, Turku, Finland \\ ${ }^{7}$ Center for Life Course Epidemiology and Systems Medicine, University of Oulu, Oulu, Finland \\ ${ }^{8}$ Unit of Primary Health Care and MRC, Oulu University Hospital, Oulu, Finland \\ ${ }^{9}$ Department of Medicine, Seinäjoki Central Hospital, Seinäjoki, Finland \\ ${ }^{10}$ Department of Endocrinology, Helsinki University Hospital and University of Helsinki, Finland \\ ${ }^{11}$ Pirkanmaa Hospital District, Finland \\ ${ }^{12}$ Tampere University Hospital, Tampere, Finland \\ ${ }^{13}$ Unit of Family Practice, Central Finland Central Hospital, Jyväskylä, Finland
}

\begin{abstract}
Background: Our aim was to study the relationship between thyroid function and body weight in a large Finnish adult population, taking into account the effect of gender, because the results of previous studies are conflicting.

Methods: A random sample of 4500 Finnish subjects aged 45-74 years old was selected from the National Population Register. The participation rate was 64\%. Height, weight, waist circumference, and blood pressure were measured. Medications used, current smoking, the use of alcohol, and leisure-time physical activity (LTPA) wereas queried. Thyroid values (free T4, free T3, and TSH) were measured in 1307 men and 1434 women. Subjects receiving thyroid hormone (N=92) were excluded.

Results: The mean age of the subjects was 59.7 years and their mean body mass index (BMI) was $27.4 \mathrm{~kg} / \mathrm{m} 2$. After adjustment for age, LTPA, and current smoking, TSH showed no linearity ( $\mathrm{p}=0.09$ ) across increasing BMI; in women TSH ranged from $1.85 \pm 1.15$ to $2.02 \pm 1.29 \mathrm{IU} / \mathrm{L}$ and in men, from $1.79 \pm 1.19$ to $2.04 \pm 1.33$ IU/L ( $p=0.13)$. FT3 -values increased from $3.85 \pm 0.67$ to $3.97 \pm 0.59 \mathrm{pmol} / \mathrm{L}$ in women $(\mathrm{p}=0.004)$, but not in men, with increasing BMI. FT4 -values decreased from $13.78 \pm 2.07$ to $13.31 \pm 1.91 \mathrm{pmol} / \mathrm{L}$ with increasing $\mathrm{BMI}$ in men ( $\mathrm{p}<0.001$ for linearity), but not in women.

Conclusions: TSH values did not increase along with BMI in men and women with BMI, but FfT3 levels increased in women, and FfT4 levels decreased in men along with increasing BMI. The reasons for these gender differences need further research.
\end{abstract}

\section{Introduction}

The growing prevalence of overweight and obesity is an important global health problem all over the world. The most recent NHANES data from the United States shows that $40 \%$ of men and 30\% of women were overweight and $35 \%$ of men and $37 \%$ of women were obese [1]. Of the Finnish adult population aged 30 years or more, $46 \%$ of men and $33 \%$ of women are overweight and $23 \%$ of men and $26 \%$ of women are obese [2]. While weight gain is largely attributable to an imbalance in energy intake and expenditure, it is also a common finding in thyroid dysfunction [3]. Resting energy expenditure (REE), which comprises around $60 \%$ of total energy expenditure in an adult man, is high in overt hyperthyroidism and low in overt hypothyroidism [4].

The association between obesity and thyroid function is complex, because overeating with accumulation of fat and the development of obesity seems to activate the hypothalamic-pituitary-thyroid axis, leading to changes in thyroid function tests, which overlap with abnormalities seen in primary thyroid disease [5].

In many studies, higher levels of thyroid stimulating hormone (TSH) are found with a higher body mass index (BMI), and the

Correspondence to: Juha Saltevo, Department of Medicine, Central Finland Central Hospital, 40620 Jyväskylä, Finland, Tel: +34 948425600; E-mail: juha. saltevo@ksshp.fi

Key words: body weight, obesity, thyroid function, gender difference, finnish population

Received: November 11, 2016; Accepted: December 12, 2016; Published: December 16, 2016 
opposite association was observed between serum free thyroxine (fT4) and BMI [6,7]. In the Norwegian Nord-Trøndelag health cohort study, associations between baseline TSH, weight, and BMI were investigated in 15020 euthyroid (serum TSH $0.5-3.5 \mathrm{mU} / \mathrm{L}$ ) individuals for 10.5 years [8]. In women, for every $1 \mathrm{mU} / \mathrm{L}$ increase in baseline serum TSH, there was a $0.9 \mathrm{~kg}$ increase in body weight and a $0.3 \mathrm{~kg} / \mathrm{m}^{2}$ increase in BMI, whereas in men the same increase was $0.8 \mathrm{~kg}$ in weight and $0.2 \mathrm{~kg} / \mathrm{m}^{2}$ in BMI [8]. Results on the association between serum free triiodothyronine (fT3) and BMI are conflicting: the Norwegian study found no association [8], yet in many studies a positive association was observed between serum fT3 and BMI $[9,10]$.

Thyroid function changes after weight loss. In a retrospective study of 258 euthyroid morbidly obese patients who underwent gastric banding, thyroid function was measured before and 24 months after the bariatric surgery. Following weight loss, fT3 levels decreased and fT4 increased, with no changes in serum TSH [11]. The mean TSH levels declined from $2.45 \mathrm{mU} / \mathrm{L}$ to $1.82 \mathrm{mU} / \mathrm{L}$, but there was no change in fT4 -levels within 6-12 months after weight loss, as determined by sleeve gastrectomy of 38 morbidly obese subjects [12].

Our aim was to study the relationship between thyroid function and body weight in a large Finnish adult population, taking into account the effect of gender, because the results of previous studies are conflicting.

\section{Materials and methods}

\section{Study population}

The FIN-D2D (Finnish Type 2 Prevention project) survey was carried out in the hospital districts of Pirkanmaa, Southern Ostrobothnia, and Central Finland between October and December 2007.

A random sample of 4500 subjects $45-74$ years old was stratified according to gender and further into 10-year age groups (45-54, 5564 , and 65-74 years) and three geographical areas. The sample was selected from the National Population Register in August 2007. The study participants were invited by mail to a clinical examination. The overall participation rate was $64 \%$. Thus, the main study included 2896 individuals, of which 1396 were men (62\% of the men invited) and 1500 were women $(66.7 \%$ of the women invited).

Thyroid values were measured in 2741 subjects (1434 women and 1307 men) in the year 2013. Thyroid hormone was used by 92 subjects. These subjects and anti-thyroid drug users were excluded from the analysis. The final study population was 2649 (1350 women and 1299 men).

The study protocol was approved by the ethics committee of the Hospital District of Helsinki. All participants gave their written, informed consent prior to participation in the study. The health examination was carried out according to the World Health Organization's (WHO) MONICA project (Multinational MONItoring of trends and determinants in CArdiovascular disease) and the WHO Expert Group for glucose assessments.

The participants reported their leisure-time physical activity (LTPA) according to three categories: 1. low: almost completely inactivate; 2 . moderate: some physical activity more than 4 hours per week; 3 . high: vigorous physical activity many times a week. Current smoking and use of alcohol were also queried. The participants were also asked whether they were using thyroid hormones or lipid-lowering, antihypertensive, antidepressive, or antihyperglycemic medications. Their history of diabetes, cancer, and cardiovascular diseases (myocardial infarction, coronary artery by-pass and angioplasty, stroke) was queried, as well.

Height, weight, and waist circumference were measured by nurses who were specially trained for the survey procedures. Height was measured to the nearest $0.1 \mathrm{~cm}$, and weight was measured to the nearest $0.1 \mathrm{~kg}$ in light clothing. Body mass index (BMI) was calculated as weight $(\mathrm{kg})$ divided by the height squared $\left(\mathrm{m}^{2}\right)$. Normal weight was categorized according to the WHO as BMI $<25.0 \mathrm{~kg} / \mathrm{m}^{2}$, overweight BMI $25.0-29.9 \mathrm{~kg} / \mathrm{m}^{2}$ and obesity with BMI $>30.0 \mathrm{~kg} / \mathrm{m}^{2}$. Blood pressure (BP) was measured twice, in a sitting position after a minimum of 15 min of acclimatization using a mercury sphygmomanometer, and the latter measurement was used in the analysis.

\section{Laboratory analysis}

After an overnight fast, venous blood samples for serum lipid assays were drawn into a gel tube containing a clot activator, and samples for a plasma glucose assay were drawn into a fluoride citrate tube (Venosafe, Terumo Europe). The samples were immediately frozen after separation of serum and plasma, and they were transferred to the laboratory in dry ice once a week for analyses. The rest of the samples were kept at $-70^{\circ} \mathrm{C}$.

Serum total cholesterol, HDL -cholesterol, triglycerides, and plasma glucose concentrations were determined enzymatically using commercial reagents from Abbott Laboratories (Abbott Park, USA) inat the Laboratory of Analytical Biochemistry at the National Public Health Institute, Helsinki (Disease Risk Unit, Institute for Health and Welfare since 2009).

Free T4 (fT4), free T3 (fT3), and TSH were measured from frozen EDTA -plasma samples with a Cobas e601 (Roche Diagnostics) automated analyzer in the Islab-laboratory of the University of Eastern Finland, Kuopio, in the year 2013. The reference values for free T4, free T3, and TSH were 11-22 pmol/L, 3.1-6.8 pmol/L, and 0.3-4.2 $\mathrm{mU} / \mathrm{L}$, respectively. Serum thyroid antiperoxidase antibodies were measured in about $30 \%$ of the study population with an Architect (Abbott Laboratories) automated analyzer. The analytical sensitivity of the assay is $0.16 \mathrm{IU} / \mathrm{mL}$ and the upper reference limit is $6.0 \mathrm{IU} / \mathrm{mL}$.

\section{Statistical analysis}

The data are presented as means with standard deviations $( \pm S D)$ or as counts with percentages. Statistical significance for hypotheses of linearity across the three BMI level groups (<25.0, 25.0-29.9 and $\geq 30.0 \mathrm{~kg} / \mathrm{m}^{2}$ ) was evaluated by one-way analysis of variance (ANOVA), Jonckheere-Terpstra test, or Cochran-Armitage test. Linearity of thyroid markers across the BMI groups was tested by using general linear models with an appropriate contrast adjusted for age, current smoking, and LTPA. In the case of a violation of the assumptions (e.g. non-normality), a bootstrap-type test was used. The normality of the variables was tested by using the Shapiro-Wilk W test.

\section{Results}

The mean age of the study population was 59.7 years (women 59.2 years and men 60.0 years). The mean BMI of both men and women was $27.4 \mathrm{~kg} / \mathrm{m}^{2}$. Table 1 shows that the use of antihypertensive, lipidlowering medication ( $<<0.001$ for linearity) and antidepressants ( $\mathrm{p}=0.006$ in women and 0.020 in men) increased in both genders with increasing BMI. Total triglycerides, fasting plasma glucose and hypertension also increased with increasing BMI ( $\mathrm{p}<0.001$ for linearity). 
Saltevo J (2016) Gender differences in thyroid function and obesity among finnish women and men. The FIN-D2D-study

Table 1. Basic demographic, clinical, and lifestyle characteristics of the study population according to BMI $<25.0,25.0-29.9$, and $\geq 30 \mathrm{~kg} / \mathrm{m}^{2} \mathrm{in}$ women and men.

\begin{tabular}{|c|c|c|c|c|}
\hline & \multicolumn{3}{|c|}{ Body Mass Index } & \multirow[t]{2}{*}{ P-value* } \\
\hline & $<25.0$ & $25.0-29.9$ & $\geq 30$ & \\
\hline \multicolumn{5}{|l|}{ Women } \\
\hline Number & 476 & 515 & 359 & \\
\hline \multicolumn{5}{|l|}{ Demographic: } \\
\hline Age, years, mean $\pm S D$ & $57 \pm 8$ & $60 \pm 8$ & $61 \pm 8$ & $<0.001$ \\
\hline Waist, $\mathrm{cm}$, mean $\pm \mathrm{SD}$ & $79 \pm 6$ & $90 \pm 6$ & $106 \pm 10$ & $<0.001$ \\
\hline \multicolumn{5}{|l|}{ Clinical: } \\
\hline \multicolumn{5}{|l|}{ Blood pressure, $\mathrm{Hg} / \mathrm{mm}$} \\
\hline Systolic, mean \pm SD & $130 \pm 18$ & $137 \pm 18$ & $141 \pm 17$ & $<0.001$ \\
\hline Diastolic, mean \pm SD & $79 \pm 9$ & $81 \pm 9$ & $83 \pm 9$ & $<0.001$ \\
\hline \multicolumn{5}{|l|}{ Biochemical: } \\
\hline Total cholesterol, $\mathrm{mmol} / \mathrm{L}$, mean $\pm \mathrm{SD}$ & $5.46 \pm 0.87$ & $5.58 \pm 0.97$ & $5.55 \pm 1.05$ & 0.15 \\
\hline HDL cholesterol, mmol/L, mean \pm SD & $1.69 \pm 0.35$ & $1.54 \pm 0.31$ & $1.38 \pm 0.27$ & $<0.001$ \\
\hline Total triglycerides, $\mathrm{mmol} / \mathrm{L}$, mean $\pm \mathrm{SD}$ & $1.01 \pm 0.40$ & $1.29 \pm 0.60$ & $1.60 \pm 0.67$ & $<0.001$ \\
\hline Fasting plasma glucose, $\mathrm{mmol} / \mathrm{L}$, mean $\pm \mathrm{SD}$ & $5.78 \pm 0.81$ & $5.99 \pm 0.92$ & $6.42 \pm 1.26$ & $<0.001$ \\
\hline \multicolumn{5}{|l|}{ Medication, $\mathrm{n}(\%)$} \\
\hline Antihypertensive medication & $100(21)$ & $174(34)$ & $178(50)$ & $<0.001$ \\
\hline Lipid-lowering medication & $45(9)$ & $105(20)$ & $88(25)$ & $<0.001$ \\
\hline Use of antidepressants & $22(5)$ & $34(7)$ & $34(9)$ & 0.006 \\
\hline \multicolumn{5}{|l|}{ Lifestyle factors, $\mathrm{n}(\%)$} \\
\hline Current smoker, n (\%) & $112(24)$ & $106(21)$ & $49(14)$ & $<0.001$ \\
\hline Leisure-time physical activity (LTPA), n (\%) & & & & $<0.001$ \\
\hline Low & $51(11)$ & $87(17)$ & $99(29)$ & \\
\hline Moderate & $296(64)$ & $303(60)$ & $191(56)$ & \\
\hline High & $119(26)$ & $116(23)$ & $50(15)$ & \\
\hline \multicolumn{5}{|l|}{ Diseases, $\mathrm{n}(\%)$} \\
\hline Cardiovascular & $12(3)$ & $20(4)$ & $15(4)$ & 0.18 \\
\hline Diabetes & $25(5)$ & $58(11)$ & $96(27)$ & $<0.001$ \\
\hline Cancer & $7(1)$ & $10(2)$ & $8(2)$ & 0.39 \\
\hline \multicolumn{5}{|l|}{ Men } \\
\hline Number & 374 & 641 & 284 & \\
\hline \multicolumn{5}{|l|}{ Demographic: } \\
\hline Age, years, mean $\pm \mathrm{SD}$ & $59 \pm 9$ & $60 \pm 8$ & $61 \pm 8$ & 0.003 \\
\hline Waist, $\mathrm{cm}$, mean $\pm \mathrm{SD}$ & $88 \pm 6$ & $100 \pm 6$ & $116 \pm 9$ & $<0.001$ \\
\hline \multicolumn{5}{|l|}{ Clinical: } \\
\hline \multicolumn{5}{|l|}{ Blood pressure, $\mathrm{Hg} / \mathrm{mm}$} \\
\hline Systolic, mean \pm SD & $133 \pm 17$ & $139 \pm 18$ & $144 \pm 18$ & $<0.001$ \\
\hline Diastolic, mean \pm SD & $80 \pm 10$ & $83 \pm 10$ & $86 \pm 10$ & $<0.001$ \\
\hline \multicolumn{5}{|l|}{ Biochemical: } \\
\hline Total cholesterol, $\mathrm{mmol} / \mathrm{L}$, mean $\pm \mathrm{SD}$ & $5.34 \pm 0.96$ & $5.36 \pm 1.01$ & $5.24 \pm 1.06$ & 0.25 \\
\hline HDL cholesterol, mmol/L, mean \pm SD & $1.45 \pm 0.33$ & $1.31 \pm 0.31$ & $1.17 \pm 0.24$ & $<0.001$ \\
\hline Total triglycerides, $\mathrm{mmol} / \mathrm{L}$, mean $\pm \mathrm{SD}$ & $1.13 \pm 0.56$ & $1.51 \pm 1.00$ & $1.94 \pm 1.26$ & $<0.001$ \\
\hline Fasting plasma glucose, $\mathrm{mmol} / \mathrm{L}$, mean $\pm \mathrm{SD}$ & $6.08 \pm 0.71$ & $6.45 \pm 1.30$ & $6.84 \pm 1.58$ & $<0.001$ \\
\hline \multicolumn{5}{|l|}{ Medication, $\mathrm{n}(\%)$} \\
\hline Antihypertensive medication & $75(20)$ & $219(34)$ & $166(58)$ & $<0.001$ \\
\hline Lipid-lowering medication & $70(19)$ & $173(27)$ & $82(29)$ & 0.002 \\
\hline Use of antidepressants & $8(2)$ & $26(4)$ & $16(6)$ & 0.020 \\
\hline \multicolumn{5}{|l|}{ Lifestyle factors, n (\%) } \\
\hline Current smoker, n (\%) & $115(31)$ & $157(24)$ & $51(18)$ & $<0.001$ \\
\hline Leisure-time physical activity (LTPA), n (\%) & & & & $<0.001$ \\
\hline Low & $54(15)$ & $101(16)$ & $94(34)$ & \\
\hline Moderate & $189(52)$ & $388(62)$ & $153(56)$ & \\
\hline High & $122(33)$ & $137(22)$ & $27(10)$ & \\
\hline \multicolumn{5}{|l|}{ Diseases, $\mathrm{n}(\%)$} \\
\hline Cardiovascular & $28(7)$ & $77(12)$ & $40(14)$ & 0.006 \\
\hline Cancer & $13(4)$ & $28(5)$ & $8(3)$ & 0.74 \\
\hline Diabetes & $38(10)$ & $122(19)$ & $109(38)$ & $<0.001$ \\
\hline
\end{tabular}

*p for linearity ANOVA, Jonckheere-Terspstra test or Cochran-Armitage test, SD = standard deviation. 
Table 2. Thyroid values and their linearity across BMI $<25.0,25.0-29.9$, and $\geq 30 \mathrm{~kg} / \mathrm{m}^{2}$ in men and women.

\begin{tabular}{|c|c|c|c|c|}
\hline & \multicolumn{3}{|c|}{ Body Mass Index $\left(\mathrm{kg} / \mathrm{m}^{2}\right)$} & \multirow[t]{2}{*}{$P$ for linearity ${ }^{1}$} \\
\hline & $\begin{array}{c}<25.0 \\
\text { Mean } \pm \text { SD }\end{array}$ & $\begin{array}{c}25.0-29.9 \\
\text { Mean } \pm \text { SD }\end{array}$ & $\begin{array}{c}\geq 30 \\
\text { Mean } \pm \text { SD }\end{array}$ & \\
\hline \multicolumn{5}{|c|}{ TSH, IU/L } \\
\hline Women & $1.85 \pm 1.15$ & $1.95 \pm 1.22$ & $2.02 \pm 1.29$ & 0.096 \\
\hline Men & $1.79 \pm 1.19$ & $1.87 \pm 1.22$ & $2.04 \pm 1.33$ & 0.13 \\
\hline \multicolumn{5}{|c|}{$\mathrm{fT} 3, \mathrm{pmol} / \mathrm{L}$} \\
\hline Women & $3.85 \pm 0.67$ & $3.90 \pm 0.65$ & $3.97 \pm 0.59$ & 0.004 \\
\hline Men & $4.11 \pm 0.67$ & $4.19 \pm 0.70$ & $4.21 \pm 0.64$ & 0.18 \\
\hline \multicolumn{5}{|c|}{ fT4, pmol } \\
\hline Women & $13.19 \pm 2.00$ & $13.07 \pm 2.04$ & $13.21 \pm 2.11$ & 0.32 \\
\hline Men & $13.78 \pm 2.07$ & $13.44 \pm 2.09$ & $13.31 \pm 1.91$ & $<0.001$ \\
\hline \multicolumn{5}{|l|}{$\mathrm{fT} 3 / \mathrm{fT} 4$} \\
\hline Women & $0.294 \pm 0.042$ & $0.302 \pm 0.045$ & $0.304 \pm 0.048$ & $<0.001$ \\
\hline Men & $0.301 \pm 0.045$ & $0.315 \pm 0.048$ & $0.319 \pm 0.048$ & $<0.001$ \\
\hline
\end{tabular}

${ }^{1}$ Adjusted for age, current smoking, and LTPA. Tested by general linear models, normality tested by Shapiro-Wilk W test; if non-normality, then a bootstrap-type test was used. SD = standard deviation

Current smoking and LTPA decreased with increasing BMI in both sexes ( $p$ for linearity $<0.001$ ). Diabetes increased with increasing BMI in women and men ( $\mathrm{p}$ for linearity $<0.001$ ). Cardiovascular diseases increased in men $(\mathrm{p}=0.006)$, but not in women. Reported cancer had no correlation with increasing $\mathrm{BMI}$ in either sex.

Table 2 shows that TSH did not show linearity across increasing BMI in women or men in the analysis adjusted for age, current smoking, and LTPA. FT3 -values increased from $3.85 \pm 0.67 \mathrm{pmol} / \mathrm{L}$ to $3.97 \pm 0.59$ $\mathrm{pmol} / \mathrm{L}$ in women $(\mathrm{p}=0.004)$, but not in men $(\mathrm{p}=0.18)$, with increasing BMI. FT4 -values decreased from $13.78 \pm 2.07 \mathrm{pmol} / \mathrm{L}$ to $13.31 \pm 1.91$ $\mathrm{pmol} / \mathrm{L}$ with increasing BMI in men $(\mathrm{p}<0.001$ for linearity), but not in women ( $\mathrm{p}=0.32$ for linearity). The fT3/fT 4 -ratio increased significantly in both sexes with increasing BMI ( $\mathrm{p}<0.001$ for linearity).

In the subpopulation whose serum TPO antibodies were measured, these results were not materially changed (data not shown). Further, substitution of waist circumference for BMI did not change the interpretation of the results.

\section{Discussion}

This Finnish population- based study found an interesting gender difference between thyroid values and BMI. In women, but not in men, serum fT3 values increased significantly with increasing BMI. However, in men, serum fT4 values decreased with higher BMI, but in women we did not find any change. The fT3/fT4 ratio increased in both sexes. In women it was due to the increased levels of fT4, while in men this increase was due to the decreased levels of fT4.

TSH values did not increase in men or women along with BMI after adjustments for age, current smoking, and LTPA. This is not in the line with a recent review of studies of the relationship between TSH and anthropometric measures in euthyroid subjects, which found that 18 of the 29 studies showed a positive relationship between adiposity and TSH [13].

The reason for the increase in fT3 found in our study only in women is not entirely clear.

A recent study analysed 3014 children who had thyroid function measured at age 7 , and also underwent dual x-ray absorptiometry scans at ages 9.9 and 15.5 years and who have genetic data available. In this study it was found that children with genetically higher BMI had higher fT3, but not fT4- levels, indicating that a higher BMI/fat mass has a causal role in increasing fT3 levels [14]. This may also explain our results where women with increasing BMI and fat mass had higher fT3-levels.

Adipocyte hormone leptin may play a role in regulating this process [15]. Leptin serves as a signal to the central nervous system regarding energy balance and the presence of energy stores. Leptin promotes thyrotropin- releasing hormone gene expression directly in the paraventricular nucleus, ultimately stimulating TSH release [1618]. Leptin may also increase $\mathrm{T} 4$ to $\mathrm{T} 3$ conversion by deiodinases in a tissue-specific fashion [19]. This has been interpreted as a defense mechanism, capable of counteracting the accumulation of fat by increasing the energy expenditure. In fact, women generally have higher weight-adjusted leptin levels than men, and this may be offer one explanation for the gender difference in the T3/T4 -ratio found herein [20]. In some studies fT3 has been shown to have no association or to be positively associated with BMI in euthyroid subjects, without gender differences. In a longitudinal study, higher fT3 and fT4 were associated with a greater risk of becoming obese over a six-year follow-up $[6,7,20-22]$. The authors thought that the changes in the thyroid hormones could be the consequence, rather than the cause, of the increase in weight [23]. In elderly subjects, baseline total T3 had no association with baseline weight or weight change over six years [24]. An interesting finding is that T3 -substitution therapy may be associated with greater weight loss compared with T4 -therapy, even with the same normal level of TSH [25]. A randomized 15-week Dutch study on the effect of T4+T3 combination therapy versus $\mathrm{T} 4$ alone for hypothyroidism also observed a greater decrease in body weight during the combined therapy [26]. An association between increased waist circumference and thyroid dysfunction, independently of overall obesity, has been found among Mexican American subjects [27]. In general, men have a larger waist circumference, and compositional changes in fat distribution may explain some of the gender differences.

Most studies have reported a general trend toward low/normal levels of fT4 in obese subjects $[14,18,28]$. A recent Tehran study had a 10-years longitudinal cohort, with 971 women and 784 men. They found in both genders a positive relationship between changes in TSH and waist circumference and a negative association between changes in fT4 levels and weight over time. FT3 -values were not measured [29]. One explanation is that reduced thyroid function measured by fT4 is a way of signalling of abundant energy reserves and consequent changes in deiodinase tissue-specific activity, promoting relatively more T3 
-production in females. Why the T3 increase in women with increasing BMI does not lower TSH is not clear, but may be due to obesity-related resistance to T3 action at the hypothalamic or hypophyseal level.

Smoking is related to both serum TSH and BMI. Smokers generally have a lower TSH concentration and BMI than non-smokers, but in some studies age and smoking status did not statistically modify the association between BMI and TSH in men or women [6,30]. In this study we adjusted the results for current smoking.

The strength of this study is rather large, randomly selected population, with both men and women aged $45-74$ years. FT4 and fT3 were collected in addition to $\mathrm{TSH}$, allowing accurate categorization of the participants according to BMI and thyroid values. We also have collected data regarding smoking, LTPA and medication for hypertension, lipids and depression, known cardiovascular diseases, cancer, and diabetes. We adjusted the data for age, current smoking, and LTPA-, men and women separately. The use of antidepressant medication and depression increased with increasing BMI. This association is known from many epidemiological studies [31,32].

The limitation of this study is its cross-sectional design and that TPO-antibodies were measured only in randomly selected $30 \%$ of the subjects. However, in this subsample TPO-antibody positivity did not alter the results. Further, the results are based on middle-aged subjects and the results cannot be generalized to younger or older agegroups. Further, one draw-back is that iodine status by urinary iodine concentration was not assessed. Despite long tradition of dietary salt supplementation, the intake of dietary iodine seems to have declined, and according to the latest estimates Finland is classified as a mild iodine deficiency area [33]. However, by definition obese people require more energy than non-obese to maintain their body mass, and therefore their dietary salt intake is not likely to be any lower than those with less body weight.

\section{Conclusions}

We found that a higher BMI was associated with higher fT3 in women, but not in men, when adjusted for age, current smoking, and LTPA in 1350 women and 1299 men not using thyroid hormone. In men, fT4 values decreased with increasing BMI, but in women we found no change. These gender differences are intriguing, and need further investigation.

\section{Author disclosure statement}

No competing financial interest exists.

\section{Funding}

FIN-D2D was supported by financing from the hospital districts of Central Finland, Pirkanmaa, Southern Ostrobothnia, North Ostrobothnia, the Finnish National Public Health Institute, the Finnish Diabetes Association, the Ministry of Social Affairs and Health in Finland, and Finland's Slot Machine Association in cooperation with the FIN-D2D Study Group.

\section{References}

1. Yang L, Colditz GA (2015) Prevalence of Overweight and Obesity in the United States, 2007-2012. JAMA Intern Med 175: 1412-1413. [Crossref]

2. Koskinen S, Lundqvist AM, Ristiluoma N (2011) Health, functional capacity and welfare in Finland.

3. Reinehr T (2010) Obesity and thyroid function. Moll Cell Endocrinol 94: 5023-5027.

4. Kim B (2008) Thyroid hormone as a determinant of energy expenditure and the basal metabolic rate. Thyroid 18: 141-144. [Crossref]

5. Laurberg P, Knudsen N, Andersen S, Carlé A, Pedersen IB, et al (2012) Thyroid function and obesity. Eur Thyroid J 1: 159-167. [Crossref]

6. Knudsen N, Laurberg P, Rasmussen LB, Bülow I, Perrild H, et al. (2005) Small differences in thyroid function may be important for body mass index and the occurrence of obesity in the population. J Clin Endocrinol Metab 90: 4019-4024. [Crossref]

7. Kitahara CM, Platz EA, Ladenson PW, Mondul AM, Menke A, et al (2012) Body fatness and markers of thyroid function among U.S. men and women. PLoS One 7: e34979. [Crossref]

8. Svare A, Nilsen TI, Bjøro T, Asvold BO, Langhammer A (2011) Serum TSH related to measures of body mass: longitudinal data from the HUNT Study, Norway. Clin Endocrinol (Oxf) 74: 769-775. [Crossref]

9. Bray GA, Fisher DA, Chopra IJ (1976) Relation of thyroid hormones to body-weight. Lancet 1: 1206-1208. [Crossref]

10. Golden SH, Robinson KA, Saldanha I, Anton B, Ladenson BW (2009). Clinical review: prevalence and incidence of endocrine and metabolic disorders in the United States: a comprehensive review. J Clin Endocrinol Metab. 94: 1853-1878. [Crossref]

11. Dall'Asta C, Paganelli M, Morabito A, Vedani P, Barbieri M, et al (2010) Weight loss through gastric banding: effects on TSH and thyroid hormones in obese subjects with normal thyroid function. Obesity (Silver Spring) 18: 854-857. [Crossref]

12. Abu-Ghanem Y, Inbar R, Tyomkin V, Kent I, Berkovich L, et al (2015) Effect of sleeve gastrectomy on thyroid hormone levels. Obes Surg 25: 452-456. [Crossref]

13. de Moura Souza A, Sichieri R (2011) Association between serum TSH concentration within the normal range and adiposity. European Journal of Endocrinology 165: 11-15. [Crossref]

14. Taylor PN, Richmond R, Davies N, Sayers A, Stevenson K, et al (2016) Paradoxical relationship between body mass index and thyroid hormone levels. A study using Mendelian randomization. J Clin Endocrinol Metab 101: 730-738. [Crossref]

15. Pearce EN (2012) Thyroid hormone and obesity. Curr Opin Endocrinol Diabetes Obes 19: 408-413. [Crossref]

16. Feldt-Rasmussen U (2007) Thyroid and leptin. Thyroid 17: 413-419. [Crossref]

17. Ghamari-Langroudi M, Srisai D, Cone RD (2011) Multinodal regulation of the arcuate/ paraventricular nucleus circuit by leptin. Proc Natl Acad Sci USA 108: 355-360. [Crossref]

18. Santini F, Marzullo P, Rotondi M, Ceccarini G, Pagano L, et al (2014) The crosstalk between thyroid gland and adipose tissue: signal integration in health and disease. European Journal of Endocrinology 171: R137-R152. [Crossref]

19. Amin A, Dhillo WS, Murphy KG (2011) The central effects of thyroid hormones on appetite. J Thyroid Res 2011: 306510. [Crossref]

20. Fulda S, Linseisen J, Wolfram G, Himmerich S, Gedrich K, et al (2010). Leptin plasma levels in the general population: influence of age, gender, body weight and medical history. Protein Pept Lett 17: 1436-1440. [Crossref]

21. Iacobellis G, Ribaudo MC, Zappaterreno A, Iannucci CV, Leonetti F (2005) Relationship of thyroid function with body mass index, leptin, insulin sensitivity and adiponectin in euthyroid obese women. Clin endocrinol (Oxf). 62: 487-491. [Crossref]

22. Alevizaki M, Saltiki K, Voidonikola P, Mantzou E, Papamichael C, et al (2009) Free thyroxine is an independent predictor of subcutaneous fat in euthyroid individuals. Eur $J$ Endocrinol 161: 459-465. [Crossref]

23. Soriguer F, Valdes S, Morcillo S, Esteva I, Almaraz MC, et al. (2011) Thyroid hormone levels predict the change in body weight: a prospective study. Eur J Clin Invest 41: 1202-1209. [Crossref]

24. Garin MC, Arnold AM, Lee JS, Tracy RP, Cappola AR (2014) Subclinical hypothyroidism, weight change, and body composition in the elderly. The Cardiovascular Health Study. J Clin Endocrinol Metab 99: 1220-1226.

25. Celi FS, Zemskova M, Linderman JD, Smith S, Drinkard B, et al (2011) Metabolic effects of liothyronine therapy in hypothyroidism: a randomized, double-blind crossover trial of liothyronine versus levothyroxine. J Clin Endocrinol Metab. 96: 3466-3474. [Crossref]

26. Appelhof BC, Fliers E, Wekking EM, Schene AH, Huyser J, et al (2005) Combined therapy with levothyroxine and liothyronine in two ratios, compared with levothyroxine monotherapy in primary hypothyroidism: a double-blind, randomized, controlled clinical trial. J Clin Endocrinol Metab 90: 2666-2674. [Crossref] 
27. Mamtani M, Kulkarni H, Dyer TD, Almasy L, Mahaney MC, et al (2014) Increased waist circumference is independently associated with hypothyroidism in Mexican Americans; replicative evidence from two large population-based studies. BMC Endocrine Disorders 14: 46. [Crossref]

28. Lee JJ, Pedley A, Marqusee E, Sutherland P, Hoffmann U, et al (2016) thyroid function and cardiovascular disease risk factors in euthyroid adults: a cross-sectional and longitudinal study. Clinical Endocrinology (Oxf) 85: 932-941. [Crossref]

29. Motamed B, Eftekharzadeh A, Hosseinpanah F, Tohidi M, Hasheminia M, et al (2016) The relation between changes in thyroid function and anthropometric indices during long-term follow-up of euthyroid subjects: the Tehran Thyroid Study (TTS). European Journal of Endocrinology 175: 247-253. [Crossref]

30. Belin RM, Astor BC, Powe NR, Ladenson PW (2004) Smoke exposure is associated with a lower prevalence of serum thyroid autoantibodies and thyrotropin concentration elevation and a higher prevalence of mild thyrotropin concentration suppression in the third National Health and Nutrition Examination Survey (NHANES III) $J$ Clin Endocrinol Metab 89: 6077-6086. [Crossref]

31. Faith MS, Butryn M, Wadden TA, Fabricatore A, Nguyen AM, et al (2011) Evidence for prospective associations among depression and obesity in population-based studies. Obes Rev 12: e438-453. [Crossref]

32. Simon GE, Von Korff M, Saunders K, Miglioretti DL, Crane PK, et al (2006) Association between obesity and psychiatric disorders in the US adult population. Arch Gen Psychiatry 63: 824-830. [Crossref]

33. Zimmermann MB, Boelaert K (2015) Iodine deficiency and thyroid disorders. Lancet Diabetes Endocrinol 3: 286-295. [Crossref]

Copyright: (C2016 Saltevo J. This is an open-access article distributed under the terms of the Creative Commons Attribution License, which permits unrestricted use, distribution, and reproduction in any medium, provided the original author and source are credited. 